\title{
KESENJANGAN ORANG TUA DALAM MEMBANGUN KOMUNIKASI YANG EFEKTIF KEPADA ANAK
}

\author{
Lusiana Herda \\ Sekolah Tinggi Agama Kristen Terpadu Pesat, Salatiga \\ Email: lusianaherda01@gmail.com
}

\begin{abstract}
Abstrak
Tujuan penelitian ini adalah mengetahui pentinganya komunikasi dan apa saja hambatan-hambatan dalam berkomunikasi yang terjadi antara orang tua dengan anak, serta memahami bagaimana berkomunikasi yang efektif dengan anak. Judul karya ilmiah ini adalah kesenjangan kesenjangan orang tua dalam membangun komunikasi yang efektif kepada anak. Metode yang digunakan adalah metode kepustakaan untuk menganalisis data tentang tujuan dari penelitian ini. Hasil penelitian menemukan bahwa kesenjangan terjadi karena orang tua kurang respek, kurang empati, tidak terbuka, dan tidak mau belajar rendah hati, untuk mendengarkan anak bicara. Oleh sebab itu, orang tua harus terbuka terhadap anak dan begitu pula sebaliknya. Sehingga, tidak menimbulkan kecurigaan yang mendatangkan kesenjangan komunikasi.
\end{abstract}

Kata Kunci : Kesenjangan, Orang tua, Komunikasi efektif, Anak.

\begin{abstract}
The purpose of this study is to know the importance of communication and what are the barriers to communication that occur between parents and children and to understand how to communicate effectively with children. The title of this scientific work is the effectiveness of parents in building good communication with their children. The method used is the library method to analyze the data about the purpose of this study. The results of the study found that this occurs because parents lack respect, lack of empathy, are not open, and do not want to learn to be humble, to listen to their children talk. Therefore, parents must be open to their children and vice versa. So, as not arouse suspicion which creates a communication gap.
\end{abstract}

Keywords :Gap, Parents, Effective communication, Children. 


\section{PENDAHULUAN}

Pasal 1 Konvensi Hak Anak secara umum mendefinisikan anak sebagai orang yang belum mencapai usia 18 tahun, namun dalam pasal tersebut juga mengakui kemungkinan adanya perbedaan atau variasi dalam penentuan batas usia kedewasaan di dalam peraturan perundangundangan dari tiap-tiap Negara Peserta. ${ }^{1} \quad$ Pengertian anak yang sangat signifikan adalah berdasarkan UndangUndang Republik Indonesia nomor 23 tahun 2002 pasal 1 ayat 1 , anak adalah seorang yang belum berusia 18 tahun, termasuk anak yang masih dalam kandungan. ${ }^{2}$ Dari pernyataan di atas mengatakan dengan jelas bahwa anak adalah orang yang belum berumur 18 tahun dan termasuk masih dalam kandungan.

Setiap anak tentunya membutuhkan perhatian dari orangtua. Orang tua adalah ayah dan /atau ibu kandung, atau ayah dan/atau ibu tiri, atau ayah dan/atau ibu angkat. ${ }^{3}$ Dari definisi di atas orang tua adalah orang yang memiliki hubungan sangat dekat, karena orang tua tersebut merupakan ayah dan ibu dari diri seorang anak. Suami, istri, dan anak merupakan

\footnotetext{
${ }^{1}$ S.H. Supriyadi W. Eddyono, "Pengantar Konvensi Hak Anak," Lembaga Studi dan Advokasi Masyarakat (2007): Hal.2.

${ }^{2}$ UU No.23 Tahun 2002 UUPA

${ }^{3}$ Ibid.,
}

keluarga sedarah unit terkecil dalam masyarakat. Serupa dengan yang terlulis dalam UU No.23. Tahun 2002 pasal 1 ayat 3 bahwa keluarga adalah unit terkecil dari suami istri, atau suami istri dan anaknya, atau ayah dan anakyaatau keluarga sedarah dalam garis lurus ke atas atau ke bawah sampai dengan derajat ketiga. Keluarga bagi anak merupakan tempat yang utama dan pertama kalinya mereka bisa membangun sosialisasi, keluarga yang dimaksud ialah orang tua dari anak itu sendiri. Ketika di dalam keluarga setiap anggota bisa saling memahami satu dengan yang lain, maka terciptalah keharmonisan, rasa saling menghormati, serta nilai-nilai moral pada anak.

Komunikasi efektif berkaitan dengan kemampuan (ability) komunikastor dan komunikasinya. Menurut Effendy (2008) komunikasi dikatakan tidak efektif diantaranya yaitu: adanya perbedaan persepsi, reaksi emosional, tidak selaras antara komunikasi verbal dan non verbal, kecurigaan, dan tidak adanya timbal balik. Rafidah. ${ }^{4} \quad$ Pentingnya komunikasi membuat individu mudah memahami pesan yang diterima dari atau tertuju pada dirinya. Sama halnya dengan pendapat

\footnotetext{
${ }^{4}$ Rafidhah Hanum, "Volume III. Nomor 1. Januari Â€'Juni 2017â',45 MENGEMBANGKAN KOMUNIKASI YANG EFEKTIF PADA ANAK USIA DINI," Bunayya: Jurnal Pendidikan Anak 3, no. 1 (2017): 45-58.
} 
Rafidhah Hanum dalam tulisannya yang mengatakan Komunikasi efektif adalah komunikasi yang dapat membuat perubahan pada sikap dan tingkah laku seseorang dalam berkomunikasi. Tujuan komunikasi adalah memberikan kemudahan dalam mendengar dan memahami pesan antara pemberi informasi dan penerima informasi. Tujuan lainnya, komunikasi memberikan kemudahan dalam memahami pesan yang disampaikan antara pemberi informasi dan penerima informasi. Dengan demikian, bahasa yang digunakan oleh pihak pemberi informasi akan lebih jelas dan mudah dimengerti. ${ }^{5}$

H.Norman Wright, mengatakan komunikasi merupakan satu suatu tindakan secara lisan maupun tulisan untuk melakukan interaksi dengan orang lain. Praktik komunikasi adalah dengan cara berbicara, mendengarkan serta memahami penjelasan dari lawan bicara. ${ }^{6}$ Dalam proses komunikasi Sulihat (2005) berpendapat bahwa orang tua perlu tahu untuk menumbuhkan sikap demokrasi dan tanggung jawab terhadap anak, orang tua melakukan dialog atau komunikasi yang terbuka, sehingga akan tercipta keterbukaan, saling menghargai,

\footnotetext{
${ }^{5}$ Ibid.

${ }^{6}$ Andreas Christanday, Komunikasi Dalam Keluarga Kristen (Yokyakarta: Penerbit Andi, 2015), Hal.2.
}

menghormati, dan sebagainya. ${ }^{7}$ Dari pernyataan tersebut orang tua berperan aktif dalam membangun komunikasi efektif. Menurut Peter dan Green (2012), dengan komunikasi yang baik akan mampu memecahkan kebuntuan dan memecahkan masalah yang muncul dalam keluarga. ${ }^{8}$ Artinya komunikasi yang baik menjadi hal mendasar bagi keluarga yaitu orang tua kepada anak ketika memecahkan suatu masalah, agar tidak terjadi kesalahpahaman yang memicu pada konflik.

Kesenjangan bisa saja terjadi dalam proses berlangsungnya komunikasi, seperti yang ditulis dalam buku yang berjudul komunikasi dalam keluarga kristen, mengatakan komunikasi merupakan "proses", maka untuk berkomunikasi yang baik membutuhkan waktu dan kesabaran karena berkomunikasi tidak sekedar saling bicara dan mendengar, tetapi juga saling mendengarkan dengan mengerti. ${ }^{9} \quad \mathrm{Hal}$ serupa dikemukakan oleh Dr.Edwin Lois Cole, dia mengatakan bahwa komunikasi bukan kemampuan berbicara, melainkan kemampuan mendengarkan. ${ }^{10}$ Artinya

\footnotetext{
${ }^{7}$ Titik Purwati, Harun Ahmad, and Dino Sudana, Komunikasi Pendidikan Bagi Keluarga TKI, ed. Dewi Kusumaningsih (Yogyakarta: BILDUNG, 2020), Hal. 7.

${ }^{8}$ Ibid., Hal.6.

${ }^{9}$ Christanday, Komunikasi Dalam Keluarga Kristen, Hal. 2.

${ }^{10}$ Christanday, Komunikasi Dalam Keluarga Kristen.
} 
orang tua maupun anak saling memberikan telinga dan mata serta mengucapkan kata-kata dengan hati jauh lebih penting dalam komunikasi. Dalam berkomunikasi seharusnya ada nilai-nilai yang positif yang menjadi patokan, untuk menuju sebuah komunikasi yang berkualitas, antara manusia dan lingkungan di sekitarnya komunikasi inilah jembatan penghubung untuk dapat berinteraksi. Tanpa komunikasi, interaksi antar manusia tidak akan terjadi.

Pengertian lain dari komunikasi dari John. R. Wenburg dan William W.Wilmot yang mengatakan bahwa komunikasi adalah usaha yang dilakukan untuk memperoleh maksud dan tujuan. Adapun menurut Donald Byker dan Loren J. Andersou komunikasi merupakan perihal berbagi informasi yang dilakukan antara dua orang atau lebih. Sedangkan menurut William I. Gorden komunikasi didefinisikan sebagai interaksi yang melibatkan melibatkan gagasan dan perasaan. ${ }^{11}$ Dengan demikian, komunikasi adalah suatu usaha yang dilakukan secara sengaja antara individu satu dengan individu lainnya, melalui proses interaksi baik secara lisan maupun tulisan yang melibatkan gagasan dan perasaan dalam diri seorang.

\footnotetext{
${ }^{11}$ Ansar Suherman, Buku Ajar Teori-Teori Komunikasi (Yogyakarta: Penerbit Deepublish, 2020).
}

\section{METODE PENELITIAN}

Penelitian dilakukan dengan metode penelitian kepustakaan. Menurut Zed (2004), yaitu serangkaian kegiatan yang berkaitan dengan pengumpulan informasi, yang diperoleh dari buku bacaan, karangan, serta tulisan mengenai suatu bidang ilmu. Pengertian tersebut dilengkapi dengan pernyataan Sugiono yang mengatakan bahwa penelitian kepustakaan adalah penelitian yang bersifat mengkaji secara teoritis, setiap fenomena yang sesuai adat istiadat, nilai, serta aturan yang berkaitan dengan budaya. $^{12}$

Penelitian kepustakaan adalah penelitian yang bersifat kualitatif, bekerja pada tataran analitik dan bersifat perspectif emic melalui memperoleh data, bukan berdasarkan pada persepsi peneliti responden atau narasumber, tetapi berdasarkan fakta-fakta konseptual maupun fakta teoris yang terjadi. ${ }^{13}$ adapun pengumpulan data pada penelitian ini diperoleh dari artikel pada portal berita online yang terpecaya, selain itu juga menggunakan jurnal publikasi yang

\footnotetext{
${ }^{12}$ Milya Sari and Asmendri Asmendri, "Penelitian Kepustakaan (Library Research) Dalam Penelitian Pendidikan IPA," Natural Science: Jurnal Penelitian Bidang IPA Dan Pendidikan IPA 6, no. 1 (2020): 41-53.

${ }^{13}$ Amir Hamzah, Metode Penelitian Kepustakaan, ed. Febi Rizki Akbar (Malang: Literrasi Nusantara, 2020).
} 
relevan dengan tujuan penelitian. Sumber data penelitian merupakan sumber data sekunder, karena data diperoleh dari buku, artikel, dan jurnal publikasi. ${ }^{14}$

Penelitian kepustakaan jelas memiliki data kualitatif dan bersifat analitik. Bukan aktifitas yang fasif, statis dan bias seperti yang diklaim Zed (2004), bahkan Furcan dan Maimun (2005) menganggap penelitian kepustakaan adalah penelitian kualitatif tingkat tinggi yang berada pada kuadran empat tingkat karena fokus pada orang dalam bidang tertentu sebagai unit analisisnya ${ }^{15}$.

\section{PEMBAHASAN}

\section{Pentingnya Komunikasi}

Komunikasi tidak terlepas dari kehidupan manusia. Komunikasi yang akurat dan baik akan menghasilkan tujuan pesan yang jelas. Sehingga, apabila kesuksesan komunikasi tidak dapat terwujudkan maka mampu menimbulkan hambatan bagi komunikator dan komunikasinya (Falletehan, 2011). ${ }^{16}$

Komunikasi antarpribadi adalah proses memberi dan menerima pesan antara individu dengan individu, individu

\footnotetext{
${ }^{14}$ Sari and Asmendri, "Penelitian Kepustakaan (Library Research) Dalam Penelitian Pendidikan IPA."

${ }^{15}$ Hamzah, Metode Penelitian Kepustakaan.

${ }^{16}$ Yossita Wisman, "Komunikasi Efektif Dalam Dunia Pendidikan," Jurnal Nomosleca 3, no. 2 (2017).
}

dengan kelompok, dan antara kelompok dengan kelompok melalui satu saluran atau lebih, dengan melibatkan umpan balik. Ketika komunikasi hendaknya orang tua dan anak melakukan komunikasi dua arah, disertai dengan sikap positif, supaya anak akan mudah menerima nasihat atau arahan. Dengan demikian, terciptanya sebuah dan hubungan yang berkualitas antara orang tua dengan anak. $^{17}$

Komunikas adalah suatu proses. Maka dari itu, untuk mendapatkan hasil yang baik memerlukan kesabaran. Dalam berkomunikasi yang efektif, seorang tidak cukup jikalau hanya berbicara dan mendengar, tetapi juga harus memahami dan mendengarkan, apa yang disampaikan. $^{18}$ Komunikasi berperan membantu perkembangan intelektual dan perkembangan sosial. Perkembangan yang dimaksud mulai dari bayi sampai masa dewasa mengikuti pola semakin meluasnya ketergantungan kita pada orang lain. ketergantungan tersebut dapat diawali dengan komunikasi yang intensif antara ibu dan anak. seiring bertambahnya usia, proses perkembangan intelektual dan perkembangan sosial Ketergantungan itu

\footnotetext{
${ }^{17}$ TEENAGERS SELF CONCEPT FROM DIVORCE FAMILY, "Konsep Diri Remaja Dari Keluarga Bercerai," Jurnal Penelitian Komunikasi Vol 18, no. 2 (2015): 129-140.

${ }^{18}$ Christanday, Komunikasi Dalam Keluarga Kristen.
} 
bertambah luas seiring bertambahnya usia manusia

Lewat komunikasi identitas seseorang akan terbentuk. Identitas atau jati diri seseorang bisa terbentuk lewat komunikasi. Selama berkomunikasi dengan anak, secara tidak langsung orang tua dapat mengamati, mencerna dan mencatat dalam hati semua tanggapan yang diberikan oleh anak terhadap diri orang tua. Kesehatan mental sebagian juga ditentukan oleh komunikasi atau interaksi yang terjalin antara orang tua dengan anak, tetapi juga dengan orang lain. Namun sebaliknya, jika terjadi masalah antara orang tua dan anak kedua belah pihak akan menderita, merasa sedih dan cemas. Karena orangtua adalah yang paling dekat dengan anak-anak mereka. Dalam rangka memahami realitas di sekeliling anak-anak anda serta menguji kebenaran kebenaran dan pengertian kita tentang dunia anak-anak. ${ }^{19}$ Agar merasa bahagia sebagai orang tua, kita membutuhkan konfirmasi dari anak dan juga orang lain, baik itu suatu hal yang bersifat menanggapi atau menunjukkan sesuatu sehingga menunjukkan bahwa diri anda mengerti.

\section{Kesenjangan Komunikasi}

Dalam proses komunikasi banyak hambatan yang dapat membuat komunikasi tidak berjalan dengan baik. Inilah yang akhirnya menimbulkan kesenjangan dalam berkomunikasi.

Kesenjangan komunikasi disebabkan antara lain yaitu: 1) kurang respect, jika orang tua memarahi atau mengkritik anak, lakukan itu dengan penuh hormat atau respek terhadap harga diri anak; 2) kurang Emphaty, orang tua perlu saling memahami dan mengerti keberadaan, perilaku dan keiinginan dari anak. Jadi sebelum membangun komunikasi dengan anak orang tua perlu mengerti dan memahami dengan rasa empati; 3) tidak terbuka, sebagai orang tua kita harus mengembangkan sikap terbuka, sehingga membantu menimbulkan sikap percaya diri pada karena tanpa keterbukaan dapat menimbulkan kecurigaan hingga berakhir pada kesenjangan komunikasi; 4) terakhir tidak belajar rendah hati, dengan menghargai anak saat berbicara, mau mendengar, menerima kritik, akan menciptakan komunikasi yang efektif.

Dalam komunikasi ada beberapa hambatan bisa diartikan dengan gangguan kebisingan dalam proses komunikasi. $^{20}$ Hambatan-hambatan dalam

\footnotetext{
${ }^{20}$ Wisman, "Komunikasi Efektif Dalam Dunia Pendidikan."
}

\footnotetext{
${ }^{19}$ A. Supratiknya, Komunikasi Antarpribadi (Yogyakarta: Penerbit Kansius, 1995).
} 
berkomunikasi yang dimaksud adalah sebagai berikut: 1) Sikap tutup mulut: 2) Mengomel menghambat komunikasi; 3) Mengritik. Beberapa hal di atas perlu diperhatikan oleh orang tua dalam membangun komunikasi yang efektif pada anak. Jika sebagai orang tua pernah atau bahkan seringkali melakukan apa yang telah dijelaskan di atas, saatnya anda merefleksi diri untuk memperbaiki hubungan komunikasi dengan anak dan mulailah mencari hal apa yang perlu dilakukan dan juga ditingkatkan selanjutnya.

\section{Komunikasi yang Efektif}

Ketika orang tua berdialog dengan anaknya maka, orang tua mendidik anak mereka bagaimana cara berpikir dengan baik. Sehingga anak akan rela melepaskan sebagian pendapatnya dengan puas. Dengarlah perasaan anak-anak anda ketika mereka berdialog dengan anda. Dialog dengan anak-anak adalah sebuah bentuk nyata dari penerjemahan, bahwa anda sebagai orang tua memberikan kebebasan penuh kepada mereka, anda tidak memaksa pendapat, anda mencurahkan rasa persahabatanmu, pengalamanmu, dan beberapa pengetahuanmu.

Ada beberapa langkah yang perlu orangtua ketahui ketika berdialog dengan anak adalah sebagai berikut:1)
Berdialoglah dengan tenang. Berikan kesempatan sebanyak-banyaknya kepada anak untuk mengungkapkan pendapatnya. Jelaskan pendapat anda dengan berbagai cara sehingga maksud tujuan anda dapat dipahami. Usahakan waktu berdiaog dengan anak anda lebih panjang. Sehingga anda tahu apa yang berkecambuk dalam akalnya. Baik itu berupa pikiran dan pendapatnya; 2) Jadilah pendengar yang aktif ketika anda berdialog dengan anakanak anda. Di saat berbicara jangan anda sibuk membaca atau menonton televisi serta kegiatan yang tidak terlalu mendesak; 3) Jangan membedakan anak anda dengan anak-anak lainnya, supaya mereka tidak sakit hati. Manfaatkan saatsaat berkumpul dengannya tanpa direncara. Biasakan anak-anak anda untuk bersikap hormat di saat berdialog dengan anda, maupun dengan orang lain. Sehingga mereka merasakan berartinya nilai dirinya. Hormatilah beberapa pendapat mereka meskipun salah sehingga kebenaran akan nampak dalam dirinya sendiri; 5) Janganlah memotong pembicaraan mereka karena akan mempengaruhi jiwa dan pikiran mereka. Berikan waktu yang luas kepada mereka untuk mengemukakan permasalahan sesuai dengan perkembangnya. ${ }^{21}$

\footnotetext{
${ }^{21}$ Abdul Jawwad and Muhammad Ahmad, Be Best Friend, ed. Fauzi Fausan and Luthfi Yanshah (Jakarta: Lini Zikrul Media Intelektual, n.d.).
} 
Sebagai orang tua, memerlukan persiapan dalam berkomunikasi. Disadari atau tidak, berkomunikasi yang baik dan benar membutuhkan persiapan walaupun persiapan itu secepat daya refleks kita. ada beberapa aspek yang harus dipersiapkan ketika sedang berkomunikasi dengan anak. Pertama, berempati adalah mencoba mengerti dan merasakan seperti apa yang anak rasakan. Kedua percaya, merupakan penolong kita untuk siap berkomunikasi; sebaliknya saling curiga akan membuat kita tidak jujur dan menutup jalur komunikasi.

Ketiga keterbukaan, antara orang tua dan anak sudah saling percaya, barulah kita saling terbuka dan jujur mengungkapkan isi hati. Keempat siap mengampuni, dalam dialog mungkin saja terjadi pengakuan kesalahan dan permohonan maaf; apapun kesalahan yang dilakukan oleh anak anda bagaimana pun mengampuni adalah hal terbaik. Anda bukan hanya sekedar membangun komunikasi yang efektif, tapi juga menjadi teladan untuk anak-anak anda. ${ }^{22}$

Untuk bisa melalakukan pengembangan dan memelihara komunikasi yang baik serta Agar mampu memulai, mengembangkan dan memelihara komunikasi yang baik hangat, dan produktif dengan anak, orang tua memiliki

\footnotetext{
${ }^{22}$ Christanday, Komunikasi Dalam Keluarga Kristen.
}

sejumlah ketrampilan dasar untuk mendapatkan hasil yang baik dari komunikasi yang efektif.

\section{KESIMPULAN}

Banyak hambatan yang menjadi pembatas atau jurang pemisah dalam setiap komunikasi, khususnya antara orang tua dan anak. Kesenjangan yang terjadi oleh orang tua dalam membangun komunikasi dengan anak di antaranya kurang respek, kurang empati, tidak terbuka dan tidak mau belajar rendah hati. Ketika bekomunikasi dengan anak ada langkah yang harus dilakukan salah satunya adalah berkomunikasi dengan tenang. Orang tua juga perlu mengetahui pentingnya komunikasi bagi kehidupan setiap manusia, terutama dalam sebuah keluarga hubungan antara orangtua dan anak serta memahami bagaimana seharusnya berkomunikasi yang efektif kepada anak. 
Fausan and Luthfi Yanshah. Jakarta:

Lini Zikrul Media Intelektual, n.d.

Purwati, Titik, Harun Ahmad, and Dino

Sudana. Komunikasi Pendidikan

Bagi Keluarga TKI. Edited by Dewi

DAFTAR PUSTAKA

Christanday, Andreas. Komunikasi Dalam

Keluarga Kristen. Yokyakarta:

Penerbit Andi, 2015.

FAMILY, TEENAGERS SELF

CONCEPT FROM DIVORCE.

“Konsep Diri Remaja Dari Keluarga

Bercerai." Jurnal Penelitian

Komunikasi Vol 18, no. 2 (2015):

129-140.

Hamzah, Amir. Metode Penelitian

Kepustakaan. Edited by Febi Rizki

Akbar. Malang: Literrasi Nusantara, 2020.

Hanum, Rafidhah. "Volume III. Nomor 1.

Januari Â€'Juni 2017â',45

MENGEMBANGKAN

KOMUNIKASI YANG EFEKTIF

PADA ANAK USIA DINI."

Bunayya: Jurnal Pendidikan Anak 3, no. 1 (2017): 45-58.

Jawwad, Abdul, and Muhammad Ahmad.

Be Best Friend. Edited by Fauzi
Kusumaningsih. Yogyakarta:

BILDUNG, 2020.

Sari, Milya, and Asmendri Asmendri.

"Penelitian Kepustakaan (Library

Research) Dalam Penelitian

Pendidikan IPA.” Natural Science:

Jurnal Penelitian Bidang IPA Dan

Pendidikan IPA 6, no. 1 (2020): 41-

53.

Suherman, Ansar. Buku Ajar Teori-Teori

Komunikasi. Yogyakarta: Penerbit

Deepublish, 2020.

Supratiknya, A. Komunikasi Antarpribadi.

Yogyakarta: Penerbit Kansius, 1995.

Supriyadi W. Eddyono, S.H. "Pengantar

Konvensi Hak Anak.” Lembaga Studi

dan Advokasi Masyarakat (2007): 17.

Wisman, Yossita. "Komunikasi Efektif

Dalam Dunia Pendidikan.” Jurnal

Nomosleca 3, no. 2 (2017). 